\title{
Microwave-Induced Combustion of Coal for Further Sulfur Determination by Inductively Coupled Plasma Optical Emission Spectrometry or Ion Chromatography
}

\author{
Gabriela Corazza, ${ }^{a}$ Alessandra S. Henn, ${ }^{a}$ Marcia F. Mesko, ${ }^{b}$ Fabio A. Duarte, ${ }^{a}$ \\ Erico M. M. Flores ${ }^{a}$ and Paola A. Mello $* a$ \\ ${ }^{a}$ Departamento de Química, Universidade Federal de Santa Maria, \\ 97105-900 Santa Maria-RS, Brazil \\ ${ }^{b}$ Centro de Ciências Químicas, Farmacêuticas e de Alimentos, \\ Universidade Federal de Pelotas, 96010-610 Pelotas-RS, Brazil
}

\begin{abstract}
In this work, a method using microwave-induced combustion (MIC) was optimized in order to obtain a fast, simple, efficient and greener sample preparation method for coal digestion and further determination of sulfur by inductively coupled plasma optical emission spectrometry (ICP OES). Accuracy was evaluated by comparison of the results with those obtained using elemental analysis by UV-fluorescence, microwave-assisted acid digestion with determination by ICP OES and by analysis of certified reference materials of coal. Some parameters that influence MIC method, such as the type and concentration of absorbing solution, the necessity of using a reflux step as well as the cooling time were carefully optimized. No statistical difference was observed for combustion without reflux followed by $5 \mathrm{~min}$ of cooling, in comparison to the reference values obtained by elemental analysis. Complete digestion was obtained with this fast and simple method (total digestion program required only $6 \mathrm{~min}$ ) and using a diluted acid solution for quantitative recovery. The feasibility of digests for sulfur determination as sulfate by ion chromatography (IC) with conductivity detection was also demonstrated. The possibility of determining other elements, commonly monitored in coals, is another advantage of this high-efficiency digestion method (MIC) combined with the multielemental capacity of ICP OES or IC instruments.
\end{abstract}

Keywords: coal, sample preparation, sulfur, MIC, ICP OES

\section{Introduction}

Despite the environmental impact related to coal combustion it remains as one of the main energy sources used worldwide. One drawback for its use is that coal contains a variety of elements that are released to the atmosphere during coal processing. ${ }^{1,2}$ Among these elements, sulfur is a major component and its combustion process contributes to the sulfur emission (as $\mathrm{SO}_{2}$ and $\mathrm{SO}_{3}$ ). In the atmosphere, those molecules can react with water resulting in acid rain, with significant environmental impacts. ${ }^{3}$ Additionally, the sulfur content also impacts on the coal price, because it is directly related to the corrosion of equipment in processing power plants and defines the technology used for the desulfurization of coal. ${ }^{4}$

*e-mail: paola.mello@ufsm.br
Due to the widespread use of coal and the importance of determining the content of sulfur, the development of a simple, fast and efficient method, in agreement with green chemistry recommendations is required. The American Society for Testing and Materials (ASTM) in ASTM D $4239-97^{5}$ method proposes the determination of sulfur in coal samples by titration. This method involves the sample burning in a furnace at $1350{ }^{\circ} \mathrm{C}$ for oxidation of sulfur to $\mathrm{SO}_{2}$ and $\mathrm{SO}_{3}$. Afterwards, determination can be carried out by acid-base or iodimetric titration, or by infrared absorption. In spite of some commercial instruments available for this purpose, the method requires calibration with certified reference materials (CRMs) and can be influenced by different species of sulfur or changes in matrix composition.

Some alternative methods have been proposed in the literature, but most of them showed the difficulties associated with coal digestion..$^{6-8}$ Alternatively, direct analysis of 
coal was proposed by Baysal and Akman, ${ }^{9}$ using a highresolution continuum source flame atomic absorption spectrophotometer by means of molecular absorption of CS formed in an air-acetylene flame. Baumbach and Einax ${ }^{10}$ used a direct solid sampling system coupled to high-resolution continuum source graphite furnace molecular absorption spectrometry (SS-HR-CS-GF MAS) for the determination of sulfur in coal by molecular absorption of $\mathrm{SnS}$. Methods based on X-ray fluorescence have been also used, but are commonly affected by poor precision and, sometimes, by matrix interferences. ${ }^{11}$ To overcome these problems, calibration with CRMs containing similar matrix or matrix matching are recommended to obtain accurate measurements. Alternatively, laser ablation inductively coupled plasma isotope dilution mass spectrometry (LA-ICP-IDMS), ${ }^{12}$ electrothermal vaporization (ETV), inductively coupled plasma optical emission spectrometry (ICP OES) and ETV inductively coupled plasma mass spectrometry (ICP-MS) ${ }^{13}$ have been also used for the determination of sulfur, sulfur species and halogens. ${ }^{14}$

Additionally, the determination of sulfur can be performed using spectrometric (ICP OES or ICP-MS) or chromatographic (ion chromatography (IC) with conductivity detection) techniques. However, these techniques conventionally require bringing the analyte into an aqueous solution. Then, an efficient sample preparation method is needed and commonly is based on dry ashing, fusion or acid dissolution. ${ }^{15}$ Despite being one of the best options for organic matrices (e.g., coal), dry ashing is susceptible to analyte losses and thus can be considered not suitable for sulfur. Regarding the fusion method, the high salt content in digests can be a problem for measurements by ICP OES..$^{15,16}$ Microwave-assisted wet digestion (MAWD) using concentrated acids $\left(\mathrm{HNO}_{3}, \mathrm{HCl}\right.$ and/or HF) for dissolution of organic and inorganic matrices is the most frequently method reported in literature. ${ }^{17-21}$ Nevertheless, high residual acidity and high carbon content in digests when digestion is not complete can interfere during elements determination by ICP OES. ${ }^{22}$ Especially for coal digestion, time consuming procedures and the use of high amounts of concentrated acids $\left(\mathrm{HNO}_{3}, \mathrm{HCl}, \mathrm{HF}\right.$ and even $\mathrm{HClO}_{4}$ ) have been commonly reported, ${ }^{8}$ despite other authors have proposed the use of $\mathrm{H}_{2} \mathrm{O}_{2}{ }^{23}$

Well-known as a high efficient method for digestion of organic matrices, combustion has been proposed for coal digestion and further determination of minor and major elements as well as for trace elements by spectrometric techniques. However, the possibility of losses of sulfur are mentioned due to the high temperature achieved inside the furnace. ${ }^{15}$ An alternative for digestion of coal is based on combustion in closed vessel, particularly suitable for volatile analytes. Geng et al. ${ }^{24}$ proposed the use of oxygen flask combustion (OFC) method for sample preparation of coal and further sulfur determination by ICP OES, using $6 \% \mathrm{H}_{2} \mathrm{O}_{2}$ as absorbing solution demonstrating the potential of combustion methods for sample preparation of coals for sulfur determination.

Among the combustion methods, microwave-induced combustion (MIC) was demonstrated to be suitable for digestion of organic matrices, bringing the analytes into the absorbing solution. The advantages of MIC are the low residual carbon content (RCC) in digests, minimizing matrix interferences, the possibility of using absorbing solutions according to the analyte and detection technique (e.g., using alkaline solutions for halogens by IC or diluted acid solution for metals by ICP OES). ${ }^{25}$ Antes et al. ${ }^{26}$ showed the feasibility of MIC for digestion of $500 \mathrm{mg}$ of coal. The absorbing solution was evaluated and diluted acid was employed. Flores et al. ${ }^{27}$ used MIC for sample preparation of coal and further determination of halogens by IC, using $50 \mathrm{mmol} \mathrm{L}^{-1}\left(\mathrm{NH}_{4}\right)_{2} \mathrm{CO}_{3}$ as absorbing solution.

In this work, a MIC method was optimized for coal digestion for further sulfur determination by ICP OES. Parameters of MIC, such as absorbing solution and heating program were investigated. Results were compared with those obtained by elemental analysis (UV-fluorescence detection) and MAWD with determination by ICP OES. Certified reference materials of coal were also used for accuracy evaluation. Suitability of digests for sulfur determination by IC was evaluated and the feasibility of MIC for simultaneous sulfur and halogens determination in coal was demonstrated.

\section{Experimental}

\section{Instrumentation}

Coal was digested by MIC using a microwave oven (Multiwave $3000^{\circledR}$ microwave sample preparation system, Anton Paar, Graz, Austria, software version v1.27-Synt) running with a maximum pressure rate of $3 \mathrm{bar} \mathrm{s}^{-1}$, which was modified from its original value $\left(0.8 \mathrm{bar} \mathrm{s}^{-1}\right)$ to avoid interrupting microwaves during the combustion of samples. This system was equipped with up to eight highpressure quartz vessels with $80 \mathrm{~mL}$ of internal volume and maximum operational temperature and pressure of $280^{\circ} \mathrm{C}$ and 80 bar, respectively. Homemade quartz holders were used to introduce the samples inside the quartz vessels. Additionally, samples of coal were digested by MAWD using the same microwave system running with a maximum pressure rate of 0.8 bar s$^{-1}$. For MAWD, this system was equipped with up to sixteen polytetrafluoroethylene (PTFE) 
vessels with $100 \mathrm{~mL}$ of internal volume and maximum operational temperature and pressure of $220^{\circ} \mathrm{C}$ and $40 \mathrm{bar}$, respectively.

Sulfur and carbon determination was performed using an ICP OES with axial view configuration (Spectro Ciros CCD, Spectral Analytical Instruments, Kleve, Germany). Instrumental parameters are described in Table 1.

Table 1. Operational conditions for the determination of sulfur and carbon by ICP OES

\begin{tabular}{lc}
\hline Parameter & ICP OES \\
\hline RF power / W & 1400 \\
Plasma gas flow rate / $\left(\mathrm{L} \mathrm{min}^{-1}\right)$ & 12 \\
Auxiliary gas flow rate / $\left(\mathrm{L} \mathrm{min}^{-1}\right)$ & 1 \\
Nebulizer gas flow rate / $\left(\mathrm{L} \mathrm{min}^{-1}\right)$ & 1 \\
Spray chamber & double pass Scott type \\
Nebulizer & cross-flow \\
Observation view & axial \\
Wavelength / nm & $\mathrm{S}(180.731)$ \\
& $\mathrm{C}(193.030)$ \\
\hline
\end{tabular}

An ion chromatograph (model 850 Professional IC, Metrohm, Herisau, Switzerland) equipped with an 858 Professional sample processor and conductivity detector was used for the determination of sulfur (as sulfate), as well as bromide, chloride and fluoride. An analytical column (Metrosep A Supp 5, Metrohm, $150 \times 4$ mm i.d., particle size $5 \mu \mathrm{m}$ and polyvinyl alcohol with quaternary ammonium groups) was used. A guard column (Metrosep A Supp 5 Guard, Metrohm) with the same material was used. Additionally, a self-regeneration suppressor from Metrohm was used to reduce the conductivity of the mobile phase. The mobile phase was composed by a solution of $3.2 \mathrm{mmol} \mathrm{L}^{-1} \mathrm{Na}_{2} \mathrm{CO}_{3}$ and $1.0 \mathrm{mmol} \mathrm{L}^{-1} \mathrm{NaHCO}_{3}$. The mobile phase flow rate was set at $0.7 \mathrm{~mL} \mathrm{~min}^{-1}$ and a sample loop of $20 \mu \mathrm{L}$ was used.

An analytical balance (AY 220, Shimadzu, Kyoto, Japan, $220 \mathrm{~g}, 0.0001 \mathrm{~g}$ of resolution) was used for weighing samples. A hydraulic press (Manual Hydraulic press 15 ton, Specac, Orpington, UK) was used for pressing samples as pellets, using 2 ton for $1 \mathrm{~min}$. For results comparison, a total sulfur analyzer (Multi EA ${ }^{\circledast}$, Analytik Jena, Jena, Germany) was used for direct determination in coal samples by UV-fluorescence, based on ASTM D 5453-03. ${ }^{28}$ Instrumental parameters are described in Table 2 . In this case, samples were directly weighed in the platforms, which were inserted into the combustion tube by an automatic auto sampler.

All statistical calculations, including Student's $t$-test (confidence level of 95\%, $p>0.05$ ) and, in some cases,
Table 2. Operational conditions for sulfur determination by UV-fluorescence using an elemental analyzer

\begin{tabular}{lc}
\hline Parameter & Value \\
\hline Combustion tube temperature $/{ }^{\circ} \mathrm{C}$ & 1050 \\
$\mathrm{O}_{2}$ flow rate (carrier) $/\left(\mathrm{mL} \mathrm{min}^{-1}\right)$ & 100 \\
time of combustion $/ \mathrm{s}$ & 90 \\
$\mathrm{O}_{2}$ flow rate $($ combustion tube $) /\left(\mathrm{mL} \mathrm{min}^{-1}\right)$ & 300 \\
Ar flow rate $($ carrier $) /\left(\mathrm{mL} \mathrm{min}^{-1}\right)$ & 100 \\
\hline
\end{tabular}

one-way analysis of variance (ANOVA) were performed using GraphPad InStat (GraphPad InStat Software Inc, San Diego, CA, USA, version 3.00, 1997) software.

Reagents, samples and solutions

Water was purified using a Milli-Q system, (Millipore, Billerica, MA, USA, $18.2 \mathrm{M} \Omega \mathrm{cm}$ ) and it was used for preparation of standards and absorbing solutions. Concentrated $\mathrm{HNO}_{3}$ (Merck, Darmstadt, Germany) was distilled in a sub-boiling system (DuoPur, Milestone, Sorisole, Italy) which was used for MAWD and as absorbing solution for MIC. Concentrated HF (40\% v/v, Sigma-Aldrich, St. Louis, MO, USA) was used without previous purification for digestion by MAWD. Ammonium nitrate solution $\left(6 \mathrm{~mol} \mathrm{~L}^{-1}\right)$ (Merck) and disks of filter paper $(15 \mathrm{~mm}$ of diameter, about $15.3 \pm 0.3 \mathrm{mg}$ ) with low ash content (Black Ribbon Ashless, Schleicher and Schuell, Dassel, Germany) were used as igniter aid for MIC. Ammonium carbonate (Merck), $\mathrm{NH}_{4} \mathrm{OH}(28 \% \mathrm{v} / \mathrm{v}$, Merck) and $\mathrm{H}_{2} \mathrm{O}_{2}(30 \% \mathrm{v} / \mathrm{v}$, Merck) were used to prepare the absorbing solutions for MIC. Salts of $\mathrm{Na}_{2} \mathrm{CO}_{3}$ (Merck) and $\mathrm{NaHCO}_{3}$ (Merck) were used to prepare the mobile phase, while $\mathrm{H}_{2} \mathrm{SO}_{4}$ (Merck) was used to prepare the solution used for suppression column regeneration.

Coal samples were obtained from coal industries from Rio Grande do Sul and Santa Catarina States, in Brazil and were named as A, B and C. The ash content in these samples ranged from 14 to $32 \%$. Certified reference materials of coal were used: National Institute of Standards and Technology (NIST) 1632c, SARM 19 from Council for Mineral Technology, Republic of South Africa and BCR 181 (coking coal) from Institute for Reference Materials and Measurements (IRMM).

A sulfur standard solution (10 mg L $\mathrm{g}^{-1}$, Spex Certiprep, Metuchen, USA) was used to prepare the calibration solutions for sulfur determination by ICP OES (from 0.1 to $10 \mathrm{mg} \mathrm{L}^{-1}$ ). For sulfur determination by UV-fluorescence using elemental analysis a white mineral oil containing $5000 \mu \mathrm{g} \mathrm{g}^{-1}$ of sulfur (AccuStandard, New Haven, CT, USA) was used to prepare analytical standards from 10 to 
$250 \mu \mathrm{g} \mathrm{g}^{-1}$ by sequential dilution in toluene (Tedia, Fairfield, $\mathrm{OH}, \mathrm{USA}$ ). A standard solution for anions (10 $\mathrm{mg} \mathrm{kg}^{-1}$, Fluka, Sigma-Aldrich, in water) was used to prepare standard solutions (from 10 to $1000 \mu \mathrm{g} \mathrm{L}^{-1}$ ) for calibration of IC instrument. For RCC determination, a stock reference solution was prepared by dissolution of citric acid (Vetec, Rio de Janeiro, Brazil) in water and yttrium (Fluka, SigmaAldrich, $1000 \mathrm{mg} \mathrm{L}^{-1}$ ) was added as internal standard (final concentration of $1 \mathrm{mg} \mathrm{L}^{-1}$ ).

For plasma generation, nebulization and as auxiliary gas, as well as a supply for the elemental analyzer, argon with a purity of 99.996\% (White Martins-Praxair Inc., São Paulo, Brazil) was used. Oxygen (99.6\%, White MartinsPraxair Inc.) was used for MIC and to supply oxygen for the elemental analyzer.

\section{Sample preparation}

\section{Microwave-induced combustion}

Microwave-induced combustion was evaluated using $250 \mathrm{mg}$ of sample which was pressed as a pellet. Pellet of sample was placed in a disk of filter paper on the quartz holder containing $50 \mu \mathrm{L}$ of $6 \mathrm{~mol} \mathrm{~L}^{-1} \mathrm{NH}_{4} \mathrm{NO}_{3}$ solution. The holder was placed inside the quartz vessel containing $6 \mathrm{~mL}$ of absorbing solution $\left(2 \mathrm{~mol} \mathrm{~L}^{-1} \mathrm{HNO}_{3}\right.$, $14 \mathrm{~mol} \mathrm{~L}^{-1} \mathrm{HNO}_{3}, \mathrm{H}_{2} \mathrm{O}, 5 \% \mathrm{H}_{2} \mathrm{O}_{2}, 50 \mathrm{mmol} \mathrm{L}^{-1} \mathrm{NH}_{4} \mathrm{OH}$ or $\left.50 \mathrm{mmol} \mathrm{L}^{-1}\left(\mathrm{NH}_{4}\right)_{2} \mathrm{CO}_{3}\right)$. The vessels were pressurized with oxygen at 20 bar for $1 \mathrm{~min}$. The microwave heating program was optimized to achieve a faster and effective digestion by MIC. Thus, the reflux step and the cooling time were evaluated from $60 \mathrm{~s}$ to $15 \mathrm{~min}$ and from 0 to $20 \mathrm{~min}$, respectively. Maximum microwave power $(1400 \mathrm{~W})$ was used to allow ignition and to maintain the heating for reflux of absorbing solution. After heating, digests were diluted with ultrapure water up to $25 \mathrm{~mL}$.

\section{Microwave-assisted digestion}

Coal samples $(250 \mathrm{mg})$ were weighed and placed into the PTFE vessels with $7 \mathrm{~mL}$ of $14 \mathrm{~mol} \mathrm{~L}^{-1} \mathrm{HNO}_{3}$ and $1 \mathrm{~mL}$ of $40 \% \mathrm{HF}$. The heating program was: (i) $1400 \mathrm{~W}$ for $40 \mathrm{~min}$ (ramp of $10 \mathrm{~min}$ ) and (ii) $0 \mathrm{~W}$ for $20 \mathrm{~min}$ (cooling step). After heating, the digests were diluted up to $25 \mathrm{~mL}$ and analyzed by ICP OES.

\section{Results and Discussion}

Optimization of MIC: sample mass, ignition and combustion time

The use of MIC as a method for digestion of organic samples has been demonstrated for many solid matrices such as petroleum coke, ${ }^{29}$ pitch, ${ }^{30}$ carbon nanotubes,${ }^{31}$ polymers, ${ }^{32}$ food and biological materials, ${ }^{33-35}$ among others. Even though MIC method can be considered simple and a general protocol can be proposed, ${ }^{36}$ a careful optimization regarding sample mass and combustion behavior must be performed. Taking into account some differences in matrices and analytes, high pressure and incomplete combustion can be observed for some materials, providing a non-quantitative analytes recovery. In these cases, some additives ${ }^{37}$ and/or changes are required in the conventional protocol..$^{38}$

Initial experiments were performed with sample masses from 100 to $500 \mathrm{mg}$ and with oxygen pressure of $20 \mathrm{bar}$, in order to achieve safe conditions during coal combustion. The increase of sample mass is important for obtaining better limits of quantification (LOQs). These results are shown in Figure 1.

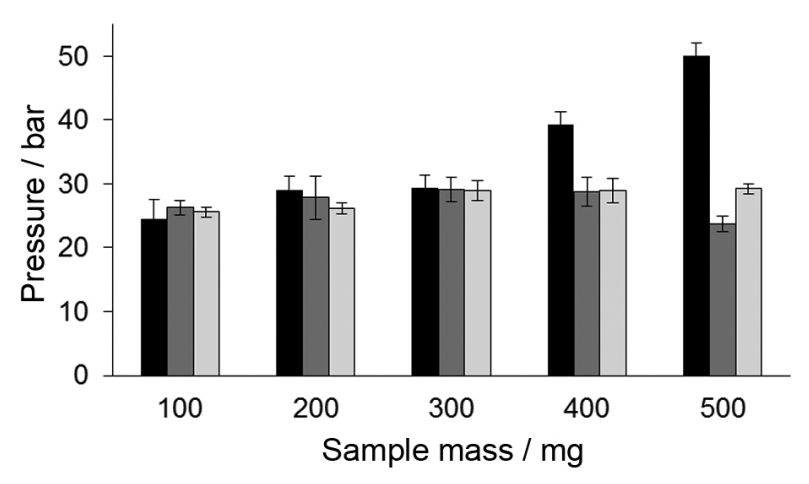

Figure 1. Maximum pressure reached during combustion of 100 to $500 \mathrm{mg}$ of coal A $(\square)$, B ( $\square)$ and C ( $\square$ ).

It is possible to see in Figure 1 that samples presented different behavior, mainly for higher sample mass (400 and $500 \mathrm{mg}$ ). This was probably a consequence of the organic content of samples (74, 53 and $30 \%$ of carbon content for samples A, B and C, respectively). Considering sample A, the combustion of $500 \mathrm{mg}$ of sample exceeded about $50 \%$ of maximum pressure that quartz vessels support ( 80 bar). Thus, due to safety reasons, $500 \mathrm{mg}$ was the maximum sample mass that was considered suitable for coal digestion using MIC. It is important to emphasize than when using coal with higher inorganic fraction (sample C), maximum pressure was only about 30 bar, allowing safe conditions. Considering the determination of sulfur in coal by ICP OES, sample mass selected for further experiments was $250 \mathrm{mg}$, since high concentration of this element is commonly found in fossil fuels. Nevertheless, this study was very important for knowing the associated risk of combustion of a given sample, and to investigate the possibility of increasing the sample mass for improving the LOQ for analytes at low concentration or for application of this method for low sulfur content coals. 
Table 3. Ignition time, combustion time and maximum pressure for coal digestion using MIC (values represent the mean and standard deviation, $\mathrm{n}=3)^{\mathrm{a}}$

\begin{tabular}{lcccc}
\hline Sample & Sample mass / $\mathrm{mg}$ & Ignition time / s & Combustion time / s & Maximum pressure / bar \\
\hline A & $247 \pm 2$ & 4 & $40 \pm 9$ & $29.4 \pm 0.5$ \\
B & $253 \pm 6$ & 5 & $53 \pm 16$ & $27.7 \pm 0.1$ \\
C & $248 \pm 2$ & 2 & $60 \pm 10$ & $26.7 \pm 0.7$ \\
\hline
\end{tabular}

${ }^{\mathrm{a}}$ Initial $\mathrm{O}_{2}$ pressure of 20 bar and $6 \mathrm{~mL} \mathrm{H}_{2} \mathrm{O}$ as absorbing solution.

In addition to the study of sample mass, the ignition time and combustion time were also investigated and results are shown in Table 3 . The ignition time ranged from 2 to $4 \mathrm{~s}$ after microwave irradiation had been started and the combustion time ranged from 40 to $60 \mathrm{~s}$. For samples with higher ash content, the complete combustion of organic fraction required longer time (about $60 \mathrm{~s}$ ), which is an important aspect considering the temperature inside the vessel for analyte recovery and the time selected for reflux of absorbing solution.

\section{Optimization of absorbing solution}

It is well established in the literature that the absorbing solution used to retain the analytes in MIC procedure is an important parameter since it can affect the analytes recovery. ${ }^{25}$ In general, to retain metals and metalloids and in order to obtain digests suitable for determination by plasmabased techniques (e.g., ICP OES and ICP-MS) the use of diluted nitric acid has been recommended. ${ }^{26}$ On the other hand, for halogens absorption and further determination by ICP OES, ICP-MS or IC, alkaline diluted solutions have been reported as more suitable. ${ }^{27,34}$ Thus, a study to select the suitable absorbing solution for sulfur was performed. Sample $\mathrm{C}$ was selected for these experiments since it presents the higher ash content and remains longer time burning. Thus, $6 \mathrm{~mL}$ of $14 \mathrm{~mol} \mathrm{~L}^{-1} \mathrm{HNO}_{3}, 2 \mathrm{~mol} \mathrm{~L}^{-1} \mathrm{HNO}_{3}, \mathrm{H}_{2} \mathrm{O}, 5 \% \mathrm{H}_{2} \mathrm{O}_{2}$, $50 \mathrm{mmol} \mathrm{L}^{-1} \mathrm{NH}_{4} \mathrm{OH}$ and $50 \mathrm{mmol} \mathrm{L}^{-1}\left(\mathrm{NH}_{4}\right)_{2} \mathrm{CO}_{3}$ were evaluated. Results were compared with those obtained using elemental analyzer by UV-fluorescence, which were used as reference for all evaluations (Figure 2).

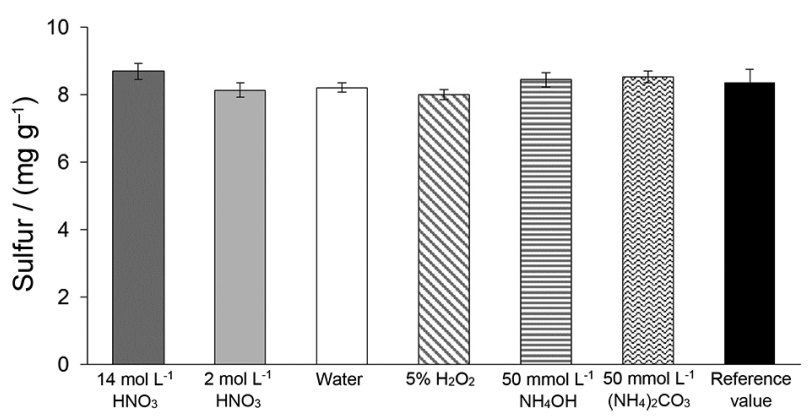

Figure 2. Evaluation of absorbing solution for sulfur recovery using MIC. Reference values (obtained using elemental analysis by UV-fluorescence) are shown for comparison ( $\mathbf{\square})$. Determination by ICP OES, $\mathrm{n}=3$.
No statistical difference $(p>0.05)$ was observed comparing all solutions and reference value. Therefore, the solution can be chosen according to the instrument selected for analyte detection or if other analytes are of interest. For example, water or alkaline solutions are suitable for the determination by IC whereas diluted $\mathrm{HNO}_{3}$ is suitable for determination by plasma-based techniques. Additionally, it is important to mention that diluted $\mathrm{HNO}_{3}, \mathrm{H}_{2} \mathrm{O}, \mathrm{H}_{2} \mathrm{O}_{2}$ or alkaline solutions show some advantages such as low consumption of reagents and low residues generation, in agreement with greening sample preparation. ${ }^{39}$

\section{Optimization of heating program}

Methods using MIC previously reported in the literature for many matrices recommend the use of at least $5 \mathrm{~min}$ of reflux for quantitative analytes recovery. ${ }^{27,33,34}$ The reflux step is commonly necessary for washing the holder and internal vessel walls, thus ensuring the recovery of analytes. This is an important advantage of MIC in comparison with OFC and combustion bomb methods..$^{36}$ Thus, the use of a reflux step was evaluated (5 and 15 min of reflux or only combustion without reflux). For these experiments, the heating program was: (i) MIC without reflux: $60 \mathrm{~s}$ of microwave irradiation $(1400 \mathrm{~W})$ for burning the sample, followed by 20 min of cooling; or (ii) MIC with reflux: 5 or 15 min of microwave irradiation $(1400 \mathrm{~W}$ ) for burning the sample and reflux of the absorbing solution, followed by 20 min of cooling. Results are shown in Figure 3a and are compared with the reference values (elemental analysis by UV-fluorescence).

From this study, no statistical difference was observed $(p>0.05)$ between the results obtained with reflux ( 5 or $15 \mathrm{~min}$ ) and without reflux in comparison with the reference value. Thus, the heating program without reflux was chosen in order to propose a fast method. An important aspect regarding the use of a reflux step is that the relative standard deviation (RSD) was about $3 \%$ using the reflux step. In contrast, when no reflux was applied the RSD was slightly worse (about 7\%), but still can be considered feasible for an analytical method. Thus, in order to propose a fast method, MIC without reflux was preferred and further experiments were carried out 


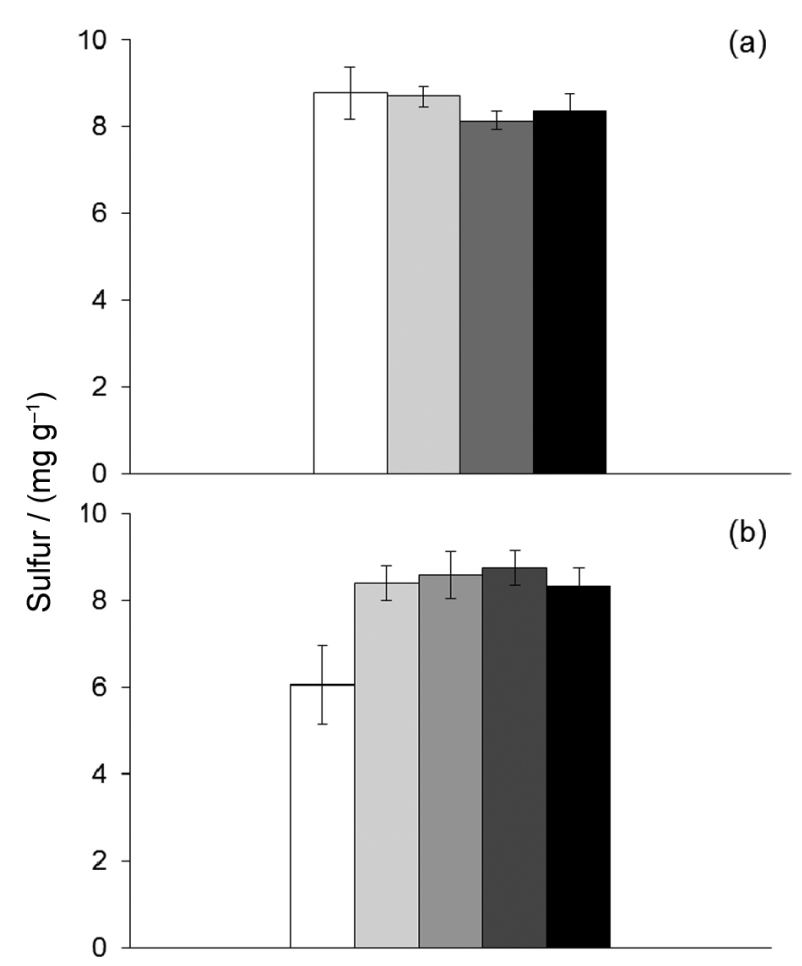

Figure 3. (a) Evaluation of reflux step after MIC: MIC without reflux step ( $\square$ ), MIC with reflux (5 min, $\square$ ) and MIC with reflux (15 min,

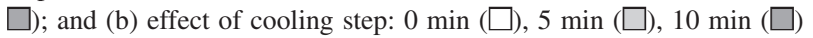
and $20 \mathrm{~min}(\square)$ on sulfur recovery. Reference values (obtained using elemental analysis by UV-fluorescence) are shown for comparison $(\square)$. Determination by ICP OES, $\mathrm{n}=3$.

to optimize the cooling step. For these experiments the heating program was set as MIC without reflux ( $60 \mathrm{~s}$ for burning the sample), followed by: (i) no cooling; (ii) $5 \mathrm{~min}$ of cooling; (iii) $10 \mathrm{~min}$ of cooling; or (iv) $20 \mathrm{~min}$ of cooling. Results are shown in Figure $3 \mathrm{~b}$.

Results obtained using no cooling time (just opening the vessels immediately after $60 \mathrm{~s}$ of combustion) were lower than the reference values (sulfur recovery about $70 \%$ ). No statistical difference was observed $(p>0.05)$ between the results obtained using 5,10 or 20 min of cooling step in comparison with the reference values. Thus, the heating program can be performed without reflux step, using just $60 \mathrm{~s}$ for sample burning followed by $5 \mathrm{~min}$ of cooling step, performing 6 min for a complete digestion program. This time can be considered as a fast sample preparation method mainly taking into account the "difficult to digest" characteristic of coal.

\section{Accuracy of MIC method and comparison with MAWD}

In order to evaluate the accuracy of the proposed MIC method, a MAWD method using concentrated $\mathrm{HNO}_{3}$ and HF was performed for results comparison. Additionally, CRMs of coal (NIST 1632c and SARM 19) were digested under optimized conditions: MIC without reflux $(1400 \mathrm{~W}$ for $60 \mathrm{~s}$ ) followed by $5 \mathrm{~min}$ of cooling using $2 \mathrm{~mol} \mathrm{~L}^{-1}$ $\mathrm{HNO}_{3}$ as absorbing solution. The results for samples A, $\mathrm{B}$ and $\mathrm{C}$ obtained by ICP OES after digestion by MIC and MAWD are shown in Table 4, as well as the results obtained using the elemental analysis by UV-fluorescence and results for CRMs.

It was possible to observe that no statistical difference was observed (ANOVA, $p>0.05$ ) by comparison of all methods for samples A, B and C. In addition, agreement with certified values was also obtained, showing the accuracy of the proposed MIC method for coal digestion and futher sulfur determination. In particular for sulfur determination by plasma-based techniques (e.g., ICP OES), the carbon content in digests is an important parameter since it can cause interferences and some problems to the equipment. So, the carbon content in digests was determined and RCC was calculated based on the original carbon content in coal samples. The RCC values by MIC were below $0.5 \%$. On the other hand, by MAWD method the RCC values were about $30 \%$. The low RCC obtained by MIC method can be atributted to the high temperature (about $1400{ }^{\circ} \mathrm{C}$ ) achieved during the coal combustion, assuring complete digestion of organic matrix and avoiding interferences in ICP OES measurements. ${ }^{27}$

Table 4. Results for sulfur determination in coals and CRMs of coal obtained by ICP OES after MIC, MAWD and elemental analysis (values represent the mean and standard deviation, $\mathrm{n}=3$ )

\begin{tabular}{lcccc}
\hline \multirow{2}{*}{ Sample } & \multicolumn{3}{c}{ Sulfur $/\left(\mathrm{mg} \mathrm{g}^{-1}\right)$} \\
\cline { 2 - 5 } & MIC & MAWD & Elemental analysis $^{\mathrm{a}}$ & Certified value \\
\hline A & $12.1 \pm 0.3$ & $12.2 \pm 0.9$ & $13.9 \pm 1.9$ & - \\
B & $16.1 \pm 0.4$ & $16.4 \pm 1.4$ & $14.3 \pm 1.7$ & - \\
C & $8.40 \pm 0.20$ & $8.57 \pm 0.36$ & $8.36 \pm 0.39$ & - \\
NIST 1632c & $13.8 \pm 0.3$ & $13.7 \pm 1.2$ & ND & $14.6 \pm 0.5$ \\
SARM 19 & $14.8 \pm 0.3$ & $14.1 \pm 0.3$ & $12.9 \pm 1.6$ & $14.9^{\mathrm{b}}$ \\
\hline
\end{tabular}

${ }^{a}$ Determination by UV-fluorescence; ${ }^{\mathrm{b}}$ confidence level is $14.2-15.5 \mathrm{mg} \mathrm{g}^{-1}$. MIC: microwave-induced combustion; MAWD: microwave-assisted wet digestion; ND: not determined. 


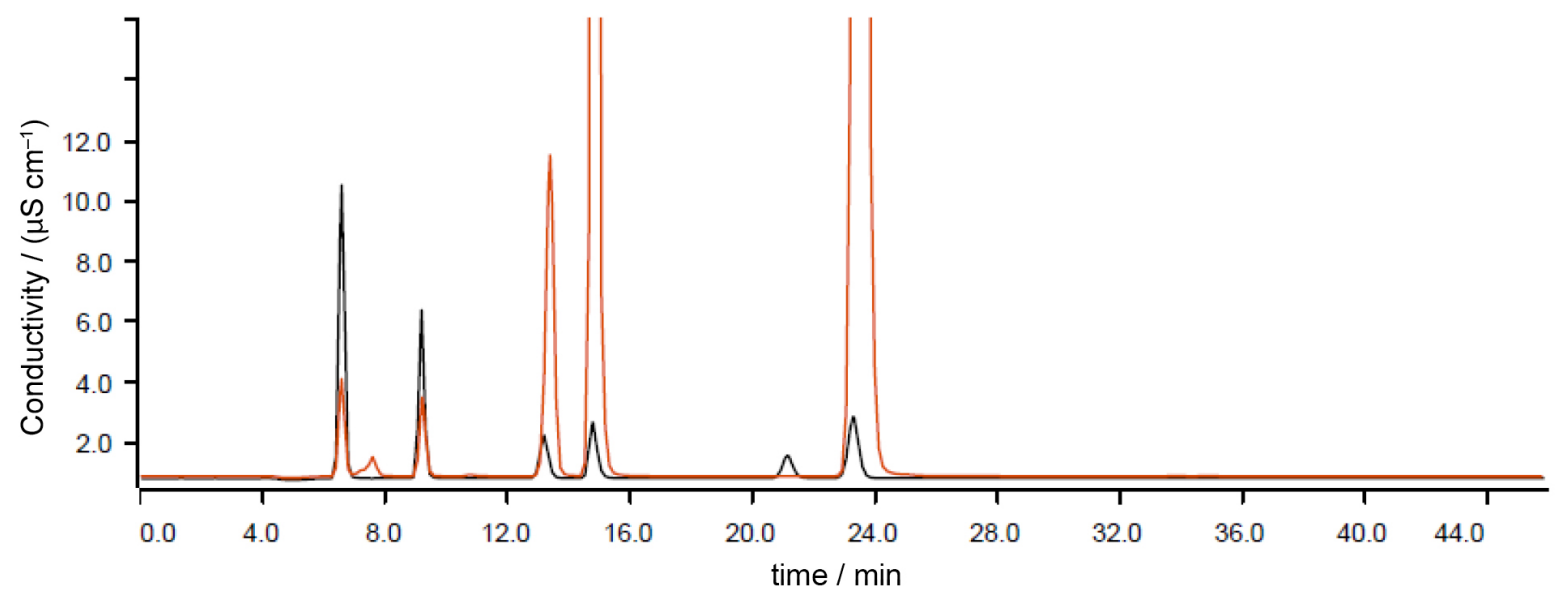

Figure 4. IC chromatograms for a $1000 \mu \mathrm{g} \mathrm{L} \mathrm{L}^{-1}$ standard solution of halogens and sulfate ( - ) and a MIC digest for coal A ( — ) diluted in water (10 times).

Another advantage of MIC in comparison with MAWD was the time required for digestion (6 min for MIC and 70 min for MAWD). In addition, the use of concentrated $\mathrm{HNO}_{3}$ and $\mathrm{HF}$ was not necessary for MIC. Despite the simplicity of using the elemental analyzer, the digestion of coal by MIC for further determination by ICP OES allows the possibility of determining other analytes

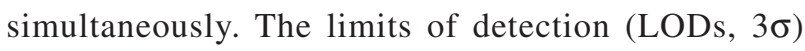
obtained by ICP OES were $2.5 \mu \mathrm{g} \mathrm{g}^{-1}$ using the proposed MIC method and $13 \mu \mathrm{g} \mathrm{g}^{-1}$ using MAWD.

Suitability of digests for IC and determination of sulfur and halogens

The possibility to determine sulfur using IC was also demonstrated taking into account that this is an instrument commonly available in many laboratories and also allows the simultaneous determination of sulfur and halogens. In this way, an alkaline solution $\left(\mathrm{NH}_{4} \mathrm{OH}\right)$ was chosen to assure quantitative absorption of halogens according to a previous work. ${ }^{27} \mathrm{~A}$ coal sample (A) and CRMs of coal (NIST 1632c, SARM 19 and BCR 181) were digested and analyzed by IC $\left(250 \mathrm{mg}\right.$ of sample, $6 \mathrm{~mL}$ of $50 \mathrm{mmol} \mathrm{L}^{-1}$ $\mathrm{NH}_{4} \mathrm{OH}$ as absorbing solution, heating program was 5 min of reflux and 20 min for cooling). The chromatograms of a $1000 \mu \mathrm{g} \mathrm{L}{ }^{-1}$ standard solution and a digest of sample A (10 times diluted in water) are shown in Figure 4.

Results obtained for sulfur (as sulfate) by IC in coal samples (A, B and C) presented no statistical difference $(p>0.05)$ in comparison with the results obtained by ICP OES. In addition, it was possible to suppose that sulfate was the only species of sulfur present after MIC which is probably a consequence of the high oxygen pressure (20 bar) during combustion. In addition, results for CRMs were in agreement with the certified values for $\mathrm{F}$ in NIST $1632 \mathrm{c}\left(70.3 \pm 3.9 \mu \mathrm{g} \mathrm{g}^{-1}\right.$ was obtained by MIC and certified value is $72.7 \pm 6.8 \mu \mathrm{g} \mathrm{g}^{-1}$ ), for $\mathrm{Cl}$ in NIST $1632 \mathrm{c}$ $\left(1114 \pm 52 \mu \mathrm{g} \mathrm{g}^{-1}\right.$ was obtained by MIC and certified value is $\left.1139 \pm 41 \mu \mathrm{g} \mathrm{g}^{-1}\right)$ and also in BCR $181\left(1404 \pm 57 \mu \mathrm{g} \mathrm{g}^{-1}\right.$ was obtained by MIC and certified value is $1380 \pm 50 \mu \mathrm{g} \mathrm{g}^{-1}$ ). For Br in SARM 19, the result obtained by MIC was lower than the $\operatorname{LOD}\left(5.3 \mu \mathrm{g} \mathrm{g}^{-1}\right)$ and the informed value is $2 \mu \mathrm{g} \mathrm{g}^{-1}$. Finally, results for sulfur (as sulfate) in CRMs obtained by IC after MIC were also in agreement with the certified values showing the feasibility of MIC for simultaneous determination of sulfur an halogens in coal.

\section{Conclusions}

The proposed MIC method was optimized for coal digestion and subsequent determination of sulfur by ICP OES. The proposed MIC method was performed without reflux followed by only 5 min of cooling step, allowing to propose a method that requires only $6 \mathrm{~min}$ for sample digestion. The results obtained by MIC for sulfur were in agreement with those obtained using MAWD and the reference values obtained using elemental analysis by UV-fluorescence. Agrement with certified values was also observed for the digestion of CRMs using MIC. Up to eight samples could be processed simultaneously in less time (only $6 \mathrm{~min}$ ) by MIC in contrast to MAWD (70 min). This can be considered advantageous for routine analysis, comprising a fast and simple method and opening new possibilities for simultaneous determination of sulfur and other analytes in coal. The suitability of digests for IC was demonstrated by the simultaneous analysis of sulfur and halogens. Using the proposed MIC method it is possible to choose the absorbing solution according to the detection technique, providing digests with negligible carbon content, minimizing interferences and contributing to a greening sample preparation method. 


\section{Acknowledgments}

The authors are grateful to Conselho Nacional de Desenvolvimento Científico e Tecnológico (CNPq), Coordenação de Aperfeiçoamento de Pessoal de Nível Superior (CAPES) and Fundação de Amparo à Pesquisa do Estado do Rio Grande do Sul (FAPERGS) for supporting this study.

\section{References}

1. Swaine, D. J.; Fuel Process. Technol. 1994, 39, 121.

2. Vejahati, F.; Xu, Z.; Gupta, R.; Fuel 2010, 89, 904.

3. Smith, R. D.; Prog. Energy Combust. Sci. 1980, 6, 53.

4. Speight, J. G.; Handbook of Coal Analysis; John Wiley \& Sons: Hoboken, 2005, pp. 222

5. ASTM D 4239-97: Standard Test Methods for Sulfur in the Analysis Sample of Coal and Coke Using High Temperature Tube Furnace Combustion Methods, West Conshohocken, 1997.

6. Wang, J.; Yamada, O.; Nakazato, T.; Zhang, Z.-G.; Suzuki, Y.; Sakamshi, K.; Fuel 2008, 87, 2211.

7. Xu, Y. H.; Iwashita, A.; Nakajima, T.; Yamashita, H.; Takanashi, H.; Ohki, A.; Talanta 2005, 66, 58.

8. Srogi, K.; Anal. Lett. 2007, 40, 199.

9. Baysal, A.; Akman, S.; Talanta 2011, 85, 2662.

10. Baumbach, G.; Einax, J. W.; Microchem. J. 2014, 117, 89.

11. Necemer, M.; Kump, P.; Rajcevic, M.; Jacimovic, R.; Budic, B.; Ponikvar, M.; Spectrochim. Acta, Part B 2003, 58, 1367.

12. Boulyga, S. F.; Heilmann, J.; Prohaska, T.; Heumann, K. G.; Anal. Bioanal. Chem. 2007, 389, 697.

13. Gois, J. S.; Pereira, E. R.; Welz, B.; Borges, D. L. G.; Anal. Chim. Acta 2014, 852, 82.

14. Bauer, D.; Vogt, T.; Klinger, M.; Masset, P. J.; Otto, M.; Anal. Chem. 2014, 86, 10380.

15. ASTM D 6349-09: Standard Test Method for Determination of Major and Minor Elements in Coal, Coke, and Solid Residues from Combustion of Coal and Coke by Inductively Coupled Plasma-Atomic Emission Spectrometry, West Conshohocken, 2009.

16. Claisse, F. In Sample Preparation for Trace Element Analysis; Mester, Z.; Sturgeon, R. E., eds.; Elsevier: Amsterdam, 2003, pp. 302.

17. Mketo, N.; Nomngongo, P. N.; Ngila, J. C.; Anal. Methods 2014, 6, 8505.

18. Low, F.; Zhang, L.; Talanta 2012, 101, 346.

19. Li, X.; Dai, S.; Zhang, W.; Li, T.; Zheng, X.; Chen, W.; Int. J. Coal Geol. 2014, 124, 1.

20. Wang, J.; Nakazato, T.; Sakanishi, K.; Yamada, O.; Tao, H.; Saito, I.; Talanta 2006, 68, 1584.

21. Ikavalko, E.; Laitinen, T.; Revitzer, H.; Fresenius'J. Anal. Chem. 1999, 363, 314.
22. Todoli, J. L.; Gras, L.; Hernandis, V.; Mora, J.; J. Anal. At. Spectrom. 2002, 17, 142.

23. Mketo, N.; Nomngongo, P. N.; Ngila, J. C.; RSC Adv. 2015, 5, 38931.

24. Geng, W.; Nakajima, T.; Takanashi, H.; Ohki, A.; Fuel 2008, $87,559$.

25. Flores, E. M. M.; Barin, J. S.; Mesko, M. F.; Knapp, G.; Spectrochim. Acta, Part B 2007, 62, 1051.

26. Antes, F. G.; Duarte, F. A.; Mesko, M. F.; Nunes, M. A. G.; Pereira, V. A.; Muller, E. I.; Dressler, V. L.; Flores, E. M. M.; Talanta 2010, 83, 364.

27. Flores, E. M. M.; Mesko, M. F.; Moraes, D. P.; Pereira, J. S. F.; Mello, P. A.; Barin, J. S.; Knapp, G.; Anal. Chem. 2008, 80, 1865.

28. ASTM D 5453-03a: Standard Test Method for Determination of Total Sulfur in Light Hydrocarbons, Motor Fuels and Motor Oils by Ultraviolet Fluorescence, West Conshohocken, 2003.

29. Mello, P. A.; Giesbrecht, C. K.; Alencar, M. S.; Moreira, E. M.; Paniz, J. N. G.; Dressler, V. L.; Flores, E. M. M.; Anal. Lett. 2008, 41, 1623.

30. Pereira, L. S. F.; Frohlich, A. C.; Duarte, F. A.; Burrow, R. A.; Muller, E. I.; Flores, E. M. M.; J. Anal. At. Spectrom. 2015, 30, 1822.

31. Mello, P. A.; Rodrigues, L. F.; Nunes, M. A. G.; Mattos, J. C. P.; Muller, E. I.; Dressler, V. L.; Flores, E. M. M.; J. Braz. Chem. Soc. 2011, 22, 1040.

32. Flores, E. M. M.; Muller, E. I.; Duarte, F. A.; Grinberg, P.; Sturgeon, R. E.; Anal. Chem. 2013, 85, 374.

33. Muller, A. L. H.; Muller, C. C.; Lyra, F.; Mello, P. A.; Mesko, M. F.; Muller, E. I.; Flores, E. M. M.; Food Anal. Methods 2013, 6, 258.

34. Picoloto, R. S.; Doneda, M.; Flores, E. L. M.; Mesko, M. F.; Flores, E. M. M.; Mello, P. A.; Spectrochim. Acta, Part B 2015, $107,86$.

35. Maciel, J. V.; Knorr, C. L.; Flores, E. M. M.; Muller, E. I.; Mesko, M. F.; Primel, E. G.; Duarte, F. A.; Food Chem. 2014, 145, 927.

36. Flores, E. M. M.; Microwave-Assisted Sample Preparation for Trace Element Determination; Elsevier: Amsterdam, 2014.

37. Mello, P. A.; Diehl, L. O.; Oliveira, J. S. S.; Muller, E. I.; Mesko, M. F.; Flores, E. M. M.; Spectrochim. Acta, Part B 2015, 105, 95.

38. Costa, V. C.; Picoloto, R. S.; Hartwig, C. A.; Mello, P. A.; Flores, E. M. M.; Mesko, M. F.; Anal. Bioanal. Chem. 2015, 407, 7957.

39. Rocha, D. L.; Batista, A. D.; Rocha, F. R. P.; Donati, G. L.; Nóbrega, J. A.; TrAC, Trends Anal. Chem. 2013, 45, 79.

Submitted: November 18, 2015

Published online: February 1, 2016

FAPERGS/CAPES has sponsored the publication of this article. 